\title{
ECS-induced amnesia: Retention function consistent with state dependency predictions*
}

\author{
TERRY L. DeVIETTI $\dagger$ and THOMAS M. HOPFER \\ Central Washington State College, Ellensburg, Washington 98926
}

\begin{abstract}
Rats were given a single fear conditioning footshock, and retention was tested in different subgroups at 24-h intervals through $144 \mathrm{~h}$ after conditioning. Under these conditions, retention was found to be strong and undifferentiated at all test intervals. However, rats given ECS 0.5 sec after the fear conditioning footshock, while evidencing amnesia at all tested intervals, showed less amnesia at 96 and $144 \mathrm{~h}$ after training and ECS. This pattern of amnesia was predicted by the state dependency hypothesis. Implications of these data regarding the role of state dependency in determining the recovery of memory following amnesia induced by a posttraining trial ECS are discussed.
\end{abstract}

Recent evidence strongly suggests that the amnesia produced by a posttraining trial ECS results from a disruption of memory-retrieval processes (see Miller \& Springer, 1973). At least two views have been advanced in this regard. In one, the retrieval-failure hypothesis (Lewis, 1969; Miller \& Springer, 1973), amnesia is considered relatively permanent, yielding only to procedures, interpolated between training-ECS and the test, designed to jog the return of memory. In general, this hypothesis has received strong experimental support (Galluscio, 1971; Lewis, Misanin, \& Miller, 1968; Miller \& Springer, 1972; Quartermain, McEwen, \& Azmitia, 1970). The other notion, the state dependency hypothesis (DeVietti \& Larson, 1971; Mayse \& DeVietti, 1971; Nielson, 1968), holds that amnesia results from an altered brain state induced by the interaction of ECS with the training-trial footshock. This hypothesis, in contrast to the retrieval-failure position, predicts the spontaneous return of memory as the altered brain state dissipates with the passage of time. This state dependency view has received support largely from experiments which have administered footshock and ECS a day or more following training, with retention tested at several intervals posttreatment. This paradigm has consistently demonstrated a transient amnesia resulting from footshock ECS (DeVietti, Holliday, \& Larson, 1973; DeVietti \& Larson, 1971; DeVietti, Mayse, \& Morris, in press). However, the evidence that the state dependency effect acts to influence the amnesia induced in the typical ECS paradigm, i.e., when ECS follows a training trial footshock, is less than compelling. While some have obtained spontaneous memory recovery under these circumstances (e.g., Cooper \& Koppenaal, 1964; Kohlenberg \& Trabasso, 1968; Nielson, 1968; Young \& Galluscio, 1971), this result has eluded many investigators (e.g., Chevalier,

*This research was supported in part by Grant GB-38790 from the National Science Foundation. We thank Craig Bucy for assisting in the collection of the data.

+Address reprint requests to Terry L. DeVietti, Department of Psychology, Central Washington State College, Ellensburg, Washington, 98926.
1965; Greenough, Schwitzgebel, \& Fulcher, 1968; Herz \& Peeke, 1967; Luttges \& McGaugh, 1967). Even when parameters have been carefully adjusted to maximize the effect (DeVietti et al, 1973; DeVietti \& Hopfer, in press $b$ ), little more than nonsignificant trends toward memory recovery have been obtained. However, a recent study (DeVietti et al, in press) may shed new light on the problem. This report provided evidence that the altered brain state resulting from footshock ECS is somewhat dependent upon ECS intensity and critically dependent upon the interval between training ECS and the test. Further, the data suggested that the altered brain state, induced by footshock ECS, tended to alternate spontaneously after initial recovery. Specifically, in the condition of interest here, rats were given footshock ECS $24 \mathrm{~h}$ after acquiring a position habit in the water T-maze. Subgroups were given retention tests at 24-h intervals up to $144 \mathrm{~h}$ after treatment. Compared to controls, experimental Ss showed amnesia up to $72 \mathrm{~h}$, followed by memory recovery at $96 \mathrm{~h}$. Amnesia was again observed at $120 \mathrm{~h}$, again followed by memory recovery at $144 \mathrm{~h}$. These data would seem to provide a rather specific baseline with which to assess the extent to which footshock-ECS-induced state dependency influences the amnesia obtained in the typical ECS paradigm. If the altered brain state, induced by footshock ECS, does influence the retention function, one would predict better retention at 96 and $144 \mathrm{~h}$ relative to $24,48,72$, and $120 \mathrm{~h}$ after the training-trial footshock and ECS. The present experiment tested this prediction.

\section{METHOD}

\section{Subjects and Apparatus}

Ss were 144 male Long-Evans rats from the Central Washington State Psychology Department animal colony, aged 90-120 days at the beginning of the experiment. The apparatus has been described in detail elsewhere (DeVietti \& Larson, 1971). Two identical chambers were used for fear conditioning and testing. They measured $9 \times 12$ in. and were $12 \mathrm{in.} \mathrm{high.} \mathrm{The}$ sides and top were constructed of Plexiglas and the back and 


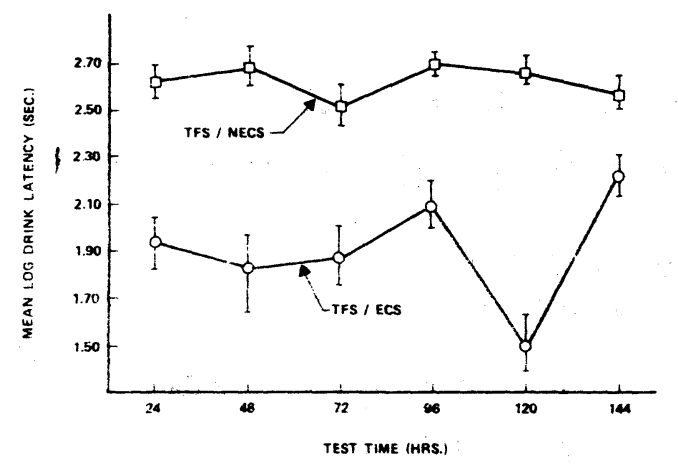

Fig. 1. Mean drink latencies ( \pm 1 standard error) in the presence of the tone for the two groups at each test interval.

front from aluminum painted flat gray. The grid floor was composed of 0.25 -in.-diam stainless steel rods spaced 0.75 in. apart. A small hole just off center in the front wall allowed the insertion of a drinking tube with the orifice located approximately $2 \mathrm{in}$. into the chamber and 2 in. above the grid floor. A drinkometer circuit was formed between the water in the drinking tube and the grid floor. A 4in. loudspeaker for delivery of the conditioned stimulus $(15-\mathrm{sec}, 1,200-\mathrm{Hz}, 75-\mathrm{dB}$ tone from a Heathkit tone generator) was positioned at floor level behind the rear wall of each chamber. Both chambers were individually enclosed in lighted, fan-ventilated, sound-attenuation boxes. Footshock, delivered through the grid floor of the conditioning chambers, was a $1.6-\mathrm{mA}$ scrambled shock ( $3 \mathrm{sec}, 60 \mathrm{~Hz}, 206 \mathrm{~V} \mathrm{rms})$. An ECS apparatus (Hayes, 1948) was set to deliver a $92-\mathrm{mA}$ shock $(200 \mathrm{msec}, 60 \mathrm{~Hz}$, $1,840 \mathrm{~V} \mathrm{rms})$ to the ears of the $\mathrm{S}$ through wire clips fashioned to interlock with baby clothes snaps (Prims No. 0) previously fitted to each ear of the S.

\section{Procedure}

The Ss were first fitted with ear snaps and then individually housed. Food was provided ad lib throughout the experiment. Water was also provided ad lib except $24 \mathrm{~h}$ prior to drink training and testing (see below). The day following individual caging, the Ss were handled for $5 \mathrm{~min}$. During the next 4 days, Ss were given experience with the various aspects of the experimental situation on the following schedule. On the first day, each $\mathrm{S}$ was placed into one of the two chambers, and left there for $10 \mathrm{~min}$. During this interval, water was removed from the home cage. The following day, each $S$ was taken to the chamber, its nose was gently touched to the drinking tube now present, and then released near the rear of the chamber. After the $S$ had completed a total of $55 \mathrm{sec}$ of contact with the drinking tube, it was returned to the home cage where water was again available. The next day, Ss were fitted with the ECS leads and placed in the chambers for $1 \mathrm{~min}$, the home cage water was again removed at this time, and Ss were again allowed to complete $55 \mathrm{sec}$ of tube contact the following day. The drinking tube was present in the chambers only during the two drink training days described above and the test days. On Day 5, Ss were randomly assigned to one of two treatment conditions.

Ss in one group (TFS/ECS) had the ECS leads attached and were individually placed into one of the two chambers. One minute later, the 15-sec tone was presented with footshock, delivered through the grid floor, occurring during the last $3 \mathrm{sec}$ of the tone. ECS followed $0.5 \mathrm{sec}$ after the offset of the tone and footshock. Ss in the other group (TFS/NECS) underwent the same procedure but did not receive ECS. Both treatment groups contained 72 Ss. Twelve Ss from each group were tested, $24 \mathrm{~h}$ thirsty, at 24-h intervals ranging from 24 through $144 \mathrm{~h}$ after training or training and ECS. After the S had completed $50 \mathrm{sec}$ of tube contact, the tone was automatically presented and remained on until the $S$ either completed an additional $5 \mathrm{sec}$ of tube contact or $600 \mathrm{sec}$ had elapsed since the tone onset. Both the time (in seconds) for the $S$ to complete the initial $50 \mathrm{sec}$ of tube contact and the time to complete an additional $5 \mathrm{sec}$ of tube contact after the presentation of the tone were automatically recorded. Ss tarrying for $600 \mathrm{sec}$ after the onset of the tone were removed from the apparatus and given a latency score of 600 .

\section{RESULTS}

Both the latencies for the initial drink and the latencies to return and complete an additional $5 \mathrm{sec}$ of contact with the drinking tube after the tone onset were transformed to logarithms and analyzed separately with a 2 by 6 factorial analysis of variance, with groups and test time serving as main effects. Analysis of the initial drink latencies revealed that this measure was not sensitive to the predicted differential retention in TFS/ECS Ss as a function of test time. Overall, TFS/NECS Ss had longer drink latencies than TFS/ECS Ss $(F=32.31, \mathrm{df}=1 / 132, \mathrm{p}<.01)$. Neither test time nor the interaction between test time and groups approached statistical reliability $(\mathrm{F}<1, \mathrm{df}=5 / 132$, $p>.05 ; F=1.48$, df $=5 / 132, p>.05$, respectively). However, the analysis of drink latencies in the presence of the tone, shown in Fig. 1, confirmed the prediction of differential retention in TFS/ECS Ss. In addition to the overall effects of groups and test time $(\mathrm{F}=145.34, \mathrm{df}=$ $1 / 132, \mathrm{p}<.01 ; \mathrm{F}=2.64, \mathrm{df}=5 / 132, \mathrm{p}<.05$, respectively), the interaction was also a reliable source of variance $(F=3.45, d f=5 / 132, p<.01)$. The breakdown of this interaction indicated that the TFS/ECS Ss, regardless of test time, had faster drink latencies than the TFS/NECS Ss (ps ranged from $<.025$ through $<.01$ ). Moreover, the TFS/NECS group showed undifferentiated retention across the tested intervals (ps $>.05)$. This finding was in marked contrast to changes in retention in the case of the TFS/ECS groups $(p<.01)$. One-tailed a priori $t$ tests compared the composite of the 24-, 48-, 72-, and 120-h groups' test performances to those of the 96-h group $(\mathrm{t}=2.79, \mathrm{df}=$ $132, \mathrm{p}<.005)$ and the $144 \mathrm{~h}$ group $(\mathrm{t}=3.84, \mathrm{df}=132$, $\mathrm{p}<.001$ ), and indicated that retention was better at these latter two intervals.

\section{DISCUSSION}

Overall, the results confirmed the state dependency prediction of differential retention in ECS Ss as a function of the training ECS to test interval. Inspection of Fig. 1 reveals that the ECS group tested at $120 \mathrm{~h}$ showed a substantial amnesia. Although amnesia at this interval was predicted, there seemed a possibility that the very small degree of retention observed at this interval might have spuriously contributed to the finding of better retention at 96 and $144 \mathrm{~h}$ when these latter groups were individually compared to the pooled results of the other ECS groups. To guard against this 
possibility, we omitted the 120-h ECS data and compared the pooled performance of the 24-, 48-, and 72-h ECS groups to both the 96- and 144-h ECS test performances. The results remained the same: both the 96- and the 144-h ECS groups showed statistically better retention than the remaining ECS groups.

The present results demonstrating alternating retention in ECS Ss, as a function of the training ECS to test interval, are quite similar to those reported by Riddell (1969), who used rats and a passive avoidance paradigm. On the basis of the present results, along with those of Riddell and others obtaining spontaneous recovery of memory following ECS, it seems likely that, under some conditions, the altered brain state resulting from the training trial footshock and ECS may contribute to the ensuing amnesia pattern. However, the effect, when obtained, appears to be weak. ECS Ss did not approach the level of retention demonstrated by the controls at any tested interval in the present experiment. Also, others, finding spontaneous memory recovery by testing independent groups of ECS Ss at various intervals, have obtained less than complete recovery (e.g., Cooper \& Koppenaal, 1964; Kohlenberg \& Trabasso, 1968) or, in cases of statistical equivalence between the ECS groups and controls, the use of some form of cut-off procedure at the test obviates any conclusions concerning the completeness of the memory recovered in ECS Ss (e.g., Nielson, 1968; Pagano, Bush, Martin, \& Hunt, 1969).

Likewise, experiments designed in support of the retrieval-failure position by interpolating a memory jog between training-ECS and the test have fared little better in demonstrating complete memory recovery. In this case, too, either incomplete recovery has been obtained (e.g., Galluscio, 1971; Miller \& Springer, 1972) or the use of a cut-off procedure at the test makes the results uninterpretable with regard to completeness of the memory recovered (e.g., Lewis et al, 1968; Quartermain et al, 1970).

It may be that neither state dependency nor retrieval-failure hypotheses are sufficient explanations of memory recovery when taken in isolation. Recent experiments from this laboratory suggest that a training trial footshock and ECS results in a retrieval deficit in which both state dependency and retrieval-failure explanations apply (DeVietti \& Hopfer, in press b). Further, combining predictions from both explanations, by administering a memory jog at an interval of high retention based on state dependency predictions, yielded the finding of complete memory recovery in ECS Ss without the contaminating factor of a ceiling limit at the test (DeVietti \& Hopfer, in press a). Perhaps one must contend with both state dependency and retrieval-failure notions to obtain a fuller understanding of memory recovery after amnesia induced by an ECS which follows a training trial footshock.

\section{REFERENCES}

Chevalier, J. A. Permanence of amnesia after a single postrial electroconvulsive seizure. Journal of Comparative \& Physiological Psychology, 1965, 59, 125-127.

Cooper, R. M., \& Koppenaal, R. J. Suppression and recovery of a one-trial avoidance response after a single ECS. Psychonomic Science, 1964, 1, 303-304.

DeVietti, T. L., Holliday, J. H., \& Larson, R. C. A comparison of the amnesias induced by ECS administered after a training trial footshock or a noncontingent footshock in rats. Journal of Comparative \& Physiological Psychology, 1973, 84, 579-585.

DeVietti, T. L., \& Hopfer, T. M. Complete amnesia induced by ECS and complete recovery of memory following reinstatement treatment. Physiology \& Behavior, 1974, in press a.

DeVietti, T. L., \& Hopfer, T. M. Reinstatement of memory in rats: Dependence upon two forms of retrieval deficit following ECS. Journal of Comparative \& Physiological Psychology, 1974, in press b.

DeVietti, T. L., \& Larson, R. C. ECS effects: Evidence supporting state-dependent learning in rats. Journal of Comparative \& Physiological Psychology, 1971, 74, 407-415.

DeVietti, T. L., Mayse, J. F., \& Morris, L. W. Footshock/ECS induced state dependent learning in rats: Parametric evaluation of ECS intensity and time of testing. Learning \& Motivation, 1974,5 , in press.

Galluscio, E. H. Retrograde amnesia induced by electroconvulsive shock and carbon dioxide anesthesia in rats: An attempt to stimulate recovery. Journal of Comparative \& Physiological Psychology, 1971, 75, 136-140.

Greenough, W. T., Schwitzgebel, R. L., \& Fulcher, J. K. Permanence of ECS-produced amnesia as a function of test conditions. Journal of Comparative \& Physiological Psychology, 1968, 66, 554-556.

Hayes, K. J. Cognitive and emotional effects of electroconvulsive shock in rats. Journal of Comparative \& Physiological Psychology, 1948, 41, 40-61.

Herz, M. J., \& Peeke, H. V. S. Permanence of retrograde amnesia produced by electroconvulsive shock. Science, 1967, 156, 1396-1397.

Kohlenberg, R., \& Trabasso, T. Recovery of a conditioned emotional response after one or two electroconvulsive shocks. Journal of Comparative \& Physiological Psychology, 1968, 65, 270-273.

Lewis, D. J. Sources of experimental amnesia. Psychological Review, 1969, 76, 461-472.

Lewis, D. J., Misanin, J. R., \& Miller, R. R. Recovery of memory following amnesia. Nature, 1968, 220, 704-705.

Luttges, M. W., \& McGaugh, J. L. Permanence of retrograde amnesia produced by electroconvulsive shock. Science, 1967, 156, 408-410.

Mayse, J. F., \& DeVietti, T. L. A comparison of state dependent learning induced by electroconvulsive shock and pentobarbital. Physiology \& Behavior, 1971, 7, 717-721.

Miller, R. R., \& Springer, A. D. Amnesia, consolidation, and retrieval, Psychological Review, 1973, 80, 69-79.

Miller, R. R., \& Springer, A. D. Induced recovery of memory in rats following electroconvulsive shock. Physiology \& Behavior, $1972,8,645-651$.

Nielson, H. C. Evidence that electroconvulsive shock alters memory retrieval rather than memory consolidation. Experimental Neurology, 1968, 20, 3-20.

Pagano, R. R., Bush, D. F., Martin, G., \& Hunt, E. B. Duration of retrograde amnesia as a function of electroconvulsive shock intensity. Physiology \& Behavior, 1969, 4, 98-105.

Quartermain, D., McEwen, B. S., \& Azmitia, E. C., Jr. Amnesia produced by electroconvulsive shock or cycloheximide: Conditions for recovery. Science, 1970, 169, 683-686.

Riddell, W. I. Effect of electroconvulsive shock: Permanent or temporary retrograde amnesia. Journal of Comparative \& Physiological Psychology, 1969, 67, 140-144.

Young, A. G., \& Galluscio, E. H. Recovery from ECS-produced amnesia. Psychonomic Science, 1971, 22, 149-151.

(Received for publication September 6, 1973; revision received December $11,1973$. 